\title{
Using the nonlinear aquifer storage-discharge relationship to simulate the base flow of glacier- and snowmelt-dominated basins in northwest China
}

\author{
R. Gan ${ }^{1,2}$ and Y. Luo ${ }^{1}$ \\ ${ }^{1}$ Key Laboratory of Ecosystem Network Observation and Modeling, Institute of Geographic Sciences and Natural Resources \\ Research, Chinese Academy of Sciences, 100101 Beijing, China \\ ${ }^{2}$ University of Chinese Academy of Sciences, 100049 Beijing, China \\ Correspondence to: Y. Luo (luoyi@igsnrr.ac.cn)
}

Received: 20 March 2013 - Published in Hydrol. Earth Syst. Sci. Discuss.: 30 April 2013

Revised: 30 July 2013 - Accepted: 9 August 2013 - Published: 25 September 2013

\begin{abstract}
Base flow is an important component in hydrological modeling. This process is usually modeled by using the linear aquifer storage-discharge relation approach, although the outflow from groundwater aquifers is nonlinear. To identify the accuracy of base flow estimates in rivers dominated by snowmelt and/or glacier melt in arid and cold northwestern China, a nonlinear storage-discharge relationship for use in SWAT (Soil Water Assessment Tool) modeling was developed and applied to the Manas River basin in the Tian Shan Mountains. Linear reservoir models and a digital filter program were used for comparisons. Meanwhile, numerical analysis of recession curves from 78 river gauge stations revealed variation in the parameters of the nonlinear relationship. It was found that the nonlinear reservoir model can improve the streamflow simulation, especially for low-flow period. The higher Nash-Sutcliffe efficiency, logarithmic efficiency, and volumetric efficiency, and lower percent bias were obtained when compared to the one-linear reservoir approach. The parameter $b$ of the aquifer storage-discharge function varied mostly between 0.0 and 0.1 , which is much smaller than the suggested value of 0.5. The coefficient $a$ of the function is related to catchment properties, primarily the basin and glacier areas.
\end{abstract}

\section{Introduction}

Base flow is an important component in hydrological modeling. This process is usually modeled by using the linear aquifer storage-discharge relationship approach due to its simplicity (e.g., Nathan and McMahon, 1990; Fenicia et al., 2006; Ferket et al., 2010). Theoretical studies of groundwater discharge have shown that a linear storage-discharge relationship describes the groundwater behavior of 1-D flow in a confined aquifer, assuming that the thickness and hydraulic conductivity are uniform (Werner and Sundquist, 1951). In this case, the logarithm of the change in discharge varies linearly with time during a recession period. However, in most cases, semi-logarithmic plots of recession curves are still concave, which indicates the nonlinearity of the aquifer storage-discharge relationship.

The linear aquifer storage-discharge relationship has been proven to be adequate (Chapman, 1999; Fenicia et al., 2006), and the prediction of the model can be improved by combining parallel linear reservoirs if the single linear reservoir fails (Moore, 1997; Luo et al., 2012). Wittenberg (1999) argued that a shallow groundwater aquifer can be divided into independent storage zones, and suggested that a nonlinear reservoir function is more realistic than linear models based on the analysis of a variety of recession curves.

The exponential function $S=a \cdot Q_{b}^{b}$ is often adapted to describe the nonlinear aquifer storage-discharge relationship. In this function the coefficient $a$ is dependent on the area, porosity, hydraulic conductivity and morphometric properties of the catchment, and the exponent $b$ is related to the 
properties of the aquifer that can be derived from streamflow records of the rivers (Wittenberg, 1994, 1999). A value of 0.5 for $b$ appears to be a standard power exponent for an unconfined aquifer (Wittenberg, 1999; Aksoy and Wittenberg, 2011). This may greatly simplify the base flow simulation. However, values for the exponent $b$ vary significantly among river catchments due to differences in the physical attributes of catchments.

The arid region of northwestern China has an area of 2.66 million square kilometers. More than $95 \%$ of the surface water in this area comes from the 576 rivers originating in the high mountains. Glaciers and snowmelt contribute 30$40 \%$ of the streamflow. Luo et al. (2012) modified the base flow component of the SWAT (Soil and Water Assessment Tool; Arnold and Fohrer, 2005) model by using two parallel linear reservoirs, achieving a much better streamflow simulation than the original single linear reservoir approach in the Manas River basin in this area.

Thus, the main objectives of this paper are to investigate (1) the performance of the nonlinear aquifer storagedischarge relation using fewer parameters in the base flow simulation in SWAT and (2) the variability of the coefficients for the rivers in the arid region of northwestern China.

\section{Materials and methods}

The performance of the nonlinear approach, the onereservoir linear approach originally provided by the SWAT model (Neitsch et al., 2002), the two-reservoir approach by Luo et al. (2012), and the automatic digital filter technique (Nathan and McMahon, 1990) can be compared.

The performance of the nonlinear base flow approach was evaluated using the Nash-Sutcliffe efficiency (NSE), the percent bias (PBIAS) (Moriasi et al., 2007) and the volumetric efficiency (VE) (Criss and Winston, 2008) indices. For the quantification of streamflow simulation, the NSE leads to an overestimation of the model performance during peak flows and an underestimation during low-flow conditions, due to the fact that the differences between the observed and simulated values are calculated as squared values (Legates and McCabe Jr., 1999). The logarithmic efficiency ( $\mathrm{NSE}_{\mathrm{log}}$ ), calculated with logarithmic values of the observed and simulated values, was also used to evaluate the performance of the model, which can reduce the problem of the squared differences and the resulting sensitivity to extreme values (Krause et al., 2005).

\subsection{The nonlinear aquifer storage-discharge function}

An exponential function has been used to describe the storage-discharge relationship (Wittenberg, 1999):

$S=a \cdot Q_{b}^{b}$,

where $S$ is the aquifer storage in $\mathrm{m}^{3}, Q_{b}$ is the discharge rate in $\mathrm{m}^{3} \mathrm{~s}^{-1}$ and the factor $a$ has the dimension of $\mathrm{m}^{3-3 b} \mathrm{~s}^{b}$.
If volumes are expressed as heights over a unit area and the time interval is a day, then the units of $a$ are in $\mathrm{mm}^{1-b} \mathrm{~d}^{b}$ and the exponent $b$ is dimensionless. The linear reservoir is thus a special case with $b=1$. Outflow from the aquifer can be derived using Eq. (1),

$Q_{b}=(S / a)^{\frac{1}{b}}$.

Based on Eq. (1) and the continuity equation of the aquifer storage,

$\mathrm{d} S / \mathrm{d} t=-Q_{b}$.

Wittenberg (1999) derived the discharge rate of the aquifer at time $t$ :

$Q_{b t}=Q_{b 0}\left[1+\frac{(1-b) Q_{b 0}^{1-b}}{a b} t\right]^{\frac{1}{b-1}}$,

where $Q_{b t}$ is the discharge rate at time $t$, and $Q_{b 0}$ is the discharge rate at the beginning of interest.

The parameters $a$ and $b$ can be calibrated by an iterative least-squares method fitting Eq. (4) to recession data (Wittenberg, 1999). The nonlinear aquifer storage-discharge function expressed by Eq. (2) is embedded into the SWAT model to simulate the base flow process.

\subsection{The automatic digital filter method}

The digital filter method was originally used in signal analysis and processing (Lyne and Hollick, 1979). Filtering direct runoff (high-frequency signals) from base flow (low-flow signals) is similar to the filtering of high-frequency signals in signal processing (Santh and Allen, 2008). The equation of the filter program is given by Nathan and McMahon (1990):

$q_{t}=\beta q_{t-1}+(1+\beta) / 2 \cdot\left(Q_{t}-Q_{t-1}\right)$,

where $q_{t}$ is the filtered direct runoff at time step $t, Q_{t}$ is the streamflow and $\beta$ is the filter parameter affecting the degree of attenuation. Base flow volume $Q_{b t}$ is calculated using the equation

$Q_{b t}=Q_{t}-q_{t}$.

According to Nathan and McMahon (1990), the value of the filter parameter that yielded the most acceptable base flow separation was in the range of 0.9-0.95, which gives the user some flexibility in adjusting the separation more accurately to approximate site conditions by choosing the filter parameter. In this study, a value of 0.925 for the filter parameter was implemented.

An automated digital filter program (Arnold et al., 1995) is used to separate base flow data from the daily streamflow data. 


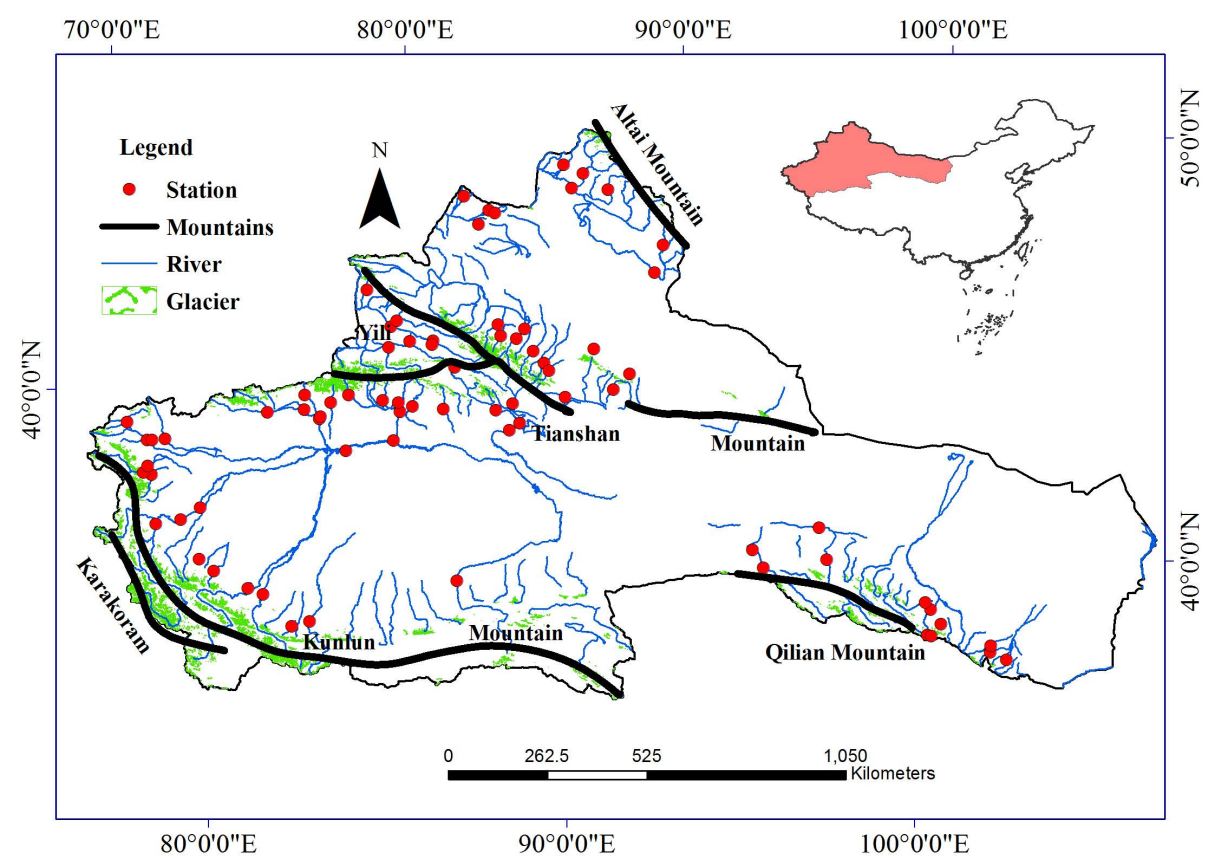

Fig. 1. Locations of river gauging stations for the study catchments.

\subsection{SWAT model setup and parameterization}

The Manas River basin (MRB) is described in detail by Luo et al. (2012). This study used the SWAT model setup and the parameters set out by Luo et al. (2012), and the parameters in Eq. (2) for the nonlinear approach were optimized. In the Manas River basin, the daily streamflow records at the Kenswat Hydrological Station (KHS) from 1961 to 1999 indicate that low flow occurs during October to March, which has been confirmed by Luo et al. (2012). The influence of groundwater evaporation on the recession can be disregarded. Therefore, the low-flow periods from October to March during 1961 to 1999 were selected to fit the recession curve. The parameters $a$ and $b$ can be optimized by fitting the calculated discharge curves to the observed recession curves by Eq. (4). Then the parameters $a$ and $b$ for the MRB were used in the SWAT model to simulate the base flow processes.

Daily streamflow data at the KHS from 1961-1999 were used. In the simulation, data from 1 January 1961 to 31 December 1980 were used for model calibration, and data from 1 January 1981 to 31 December 1999 were used for validation. Model calibration was conducted by comparing the SWAT simulation to the streamflow observation at the KHS on a daily basis.

The parameters $a$ and $b$ were also analyzed for 78 other basins in this region (Fig. 1) to investigate their variability among different basins and their relationships to the catchment attributes. The maximum catchment area reaches $50763 \mathrm{~km}^{2}$, while the minimum was just $229 \mathrm{~km}^{2}$ with a mean value of $9841 \mathrm{~km}^{2}$, and the glacier information on the study catchments (Yang, 1991) is listed in Table 1.
Table 1. Statistical analysis for the selected catchment characteristics in the study.

\begin{tabular}{lrrrr}
\hline & Min & Max & Mean & Std dev \\
\hline Catchment area $\left(\mathrm{km}^{2}\right)$ & 229 & 50763 & 9841 & 12936 \\
Glacier area $\left(\mathrm{km}^{2}\right)$ & 0 & 3265 & 485 & 791 \\
Glacier cover ratio $(\%)$ & 0 & 46 & 7 & 10 \\
\hline
\end{tabular}

\section{Results and discussion}

\subsection{Aquifer storage-discharge relationship for the MRB}

The aquifer discharge does not show a linear change over time on the semi-log plot (Fig. 2). This may be due to complex factors such as climate, topography, land cover (such as snow and glaciers), soil types and catchment geology (Haberlandt et al., 2001; Mwakalila et al., 2002; Longobardi and Villani, 2008).

The optimized values for $a$ and $b$ are listed in Table 2, and the recession curves simulated using Eq. (4) with these values are presented in Fig. 2. Surprisingly, the value of $b$ is far less than the suggested value, which is approximately 0.5 (Wittenberg, 1994, 1999). Due to an exponent as small as 0.025 , the aquifer discharge rate appears to be strongly related to the aquifer storage. The recession data calculated using Eq. (4) were compared to the observed data and those calculated using the linear relation. Compared to the observed low flow, the linear relation underestimates the discharge in 
Table 2. Parameter values of the exponential aquifer storagedischarge function for the Manas River basin, Xinjiang, China.

\begin{tabular}{lccc}
\hline Approach & Parameter & $\begin{array}{c}\text { Calibrated } \\
\text { value }\end{array}$ & $R^{2}$ \\
\hline Nonlinear storage-discharge function & $a$ & 771.6 & 0.90 \\
& $b$ & 0.025 & \\
\hline
\end{tabular}

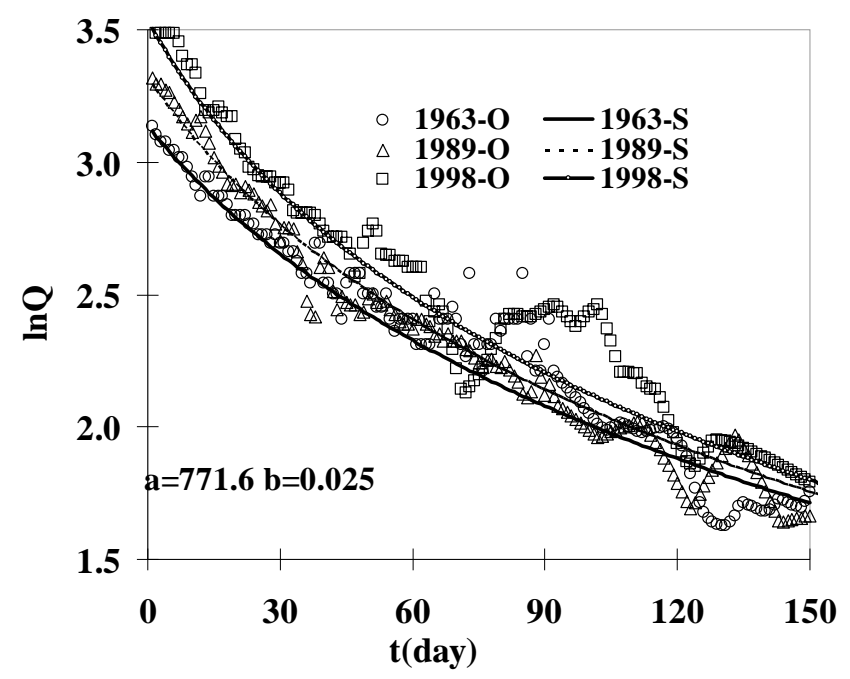

Fig. 2. Recession curves of $\ln Q-t$ for typical years in the Manas River basin (O - observed data; $\mathrm{S}$ - simulated data).

the low range and overestimates it in the mid- and upper ranges (Fig. 3a), while the nonlinear relation estimates the discharge well for the low and mid-ranges and slightly underestimates it in the upper range (Fig. 3b). Generally, the nonlinear relation performs better than the linear relation.

\subsection{The simulated streamflow}

The performances of the different base flow simulation approaches are presented in Table 3. The NSE and PBIAS indicate that the one-nonlinear reservoir method and the two-linear reservoir method both yield "good" or "very good" results based on the rating rules given by Moriasi et al. (2007), which are better than the original one-linear reservoir method. The $\mathrm{NSE}_{\mathrm{log}}$ and VE for one-nonlinear reservoir method are higher than those for the one-linear reservoir method. The differences in the evaluation indices for the twolinear and the one-nonlinear approaches are very small, and often even higher values are achieved for the two-linear approach. The one-nonlinear reservoir approach has some advantages over the two-linear reservoir approach in parameterization. The two-linear reservoir approach has five parameters that need to be calibrated within the model (Luo et al., 2012). However, the one-nonlinear approach has only two parameters. These parameters can be calibrated indepen-
Table 3. Efficiency measures for the Manas River basin using the different base flow approaches.

\begin{tabular}{llrrrr}
\hline Model & Segment & NSE & NSE $_{\log }$ & PBIAS & VE \\
\hline \multirow{3}{*}{ One-linear reservoir } & calibration & 0.68 & -4.93 & -4.0 & 0.59 \\
& validation & 0.62 & -4.9 & -3.5 & 0.56 \\
& overall & 0.65 & -4.91 & -3.7 & 0.57 \\
\hline \multirow{3}{*}{ Two-linear reservoir } & calibration & 0.76 & 0.88 & -2.6 & 0.70 \\
& validation & 0.69 & 0.87 & -3.6 & 0.67 \\
& overall & 0.72 & 0.88 & -3.2 & 0.68 \\
\hline \multirow{3}{*}{ One-nonlinear reservoir } & calibration & 0.74 & 0.87 & 1.8 & 0.69 \\
& validation & 0.70 & 0.88 & -3.2 & 0.67 \\
& overall & 0.72 & 0.87 & -1.1 & 0.68 \\
\hline
\end{tabular}

dently of the model by using the low-flow record and the discharge recession equation as in Wittenberg (1999).

The nonlinear approach in Eq. (2) overestimates the annual streamflow volume by $1.1 \%$, and the two-linear reservoir approach overestimates it by $3.1 \%$. Slight differences between the simulated and measured annual streamflow exist for the two-linear reservoir and one-nonlinear base flow simulation approaches.

The streamflow processes simulated by the SWAT model using different base flow approaches were compared to the measured values. A five-year period of data at validation stage was taken as an example (Fig. 4). In general, the simulated streamflow processes show a similar trend to those observed for the different models. The streamflow starts to rise in late April due to snowmelt. The glacier begins to melt when the snowpack depletes, and the streamflow continues to rise until the peak value in late July. Then the streamflow recedes until the glacier ceases to melt in late September, after which the streamflow remains in a relatively stable recession until the next April. This is a common feature of rivers dominated by snow/glacier melt in northwestern China. The simulated streamflow is not well correlated with the measured streamflow during the high-flow period. This may be attributed to the snowmelt simulation (Arnold et al., 2000). Luo et al. (2012) thought that these differences might be due to the meteorological speculation in mountainous areas for the SWAT model, which are derived from the records at the foot of the mountain using a single precipitation lapse rate. During the low-flow period, the one-linear reservoir model underestimates the streamflow significantly, while the onenonlinear reservoir model and two-linear reservoir model improve the simulation remarkably (Fig. 4).

\subsection{The simulated base flow}

The simulated base flow and surface runoff hydrographs using the one-nonlinear reservoir model are shown in Fig. 5. During the low-flow period, base flow contributes considerably more than surface runoff to the streamflow due to less precipitation and melting water. However, during the 

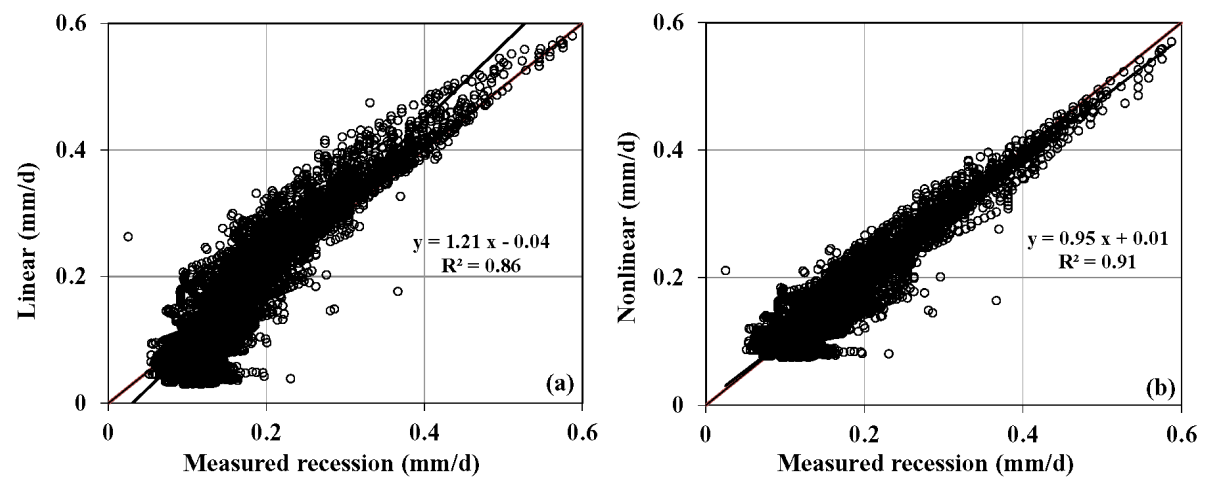

Fig. 3. Comparison of the fitted and measured recession data for 1961-1999 in the Manas River basin: (a) using the linear aquifer storagedischarge relation; (b) using the nonlinear aquifer storage-discharge relation.
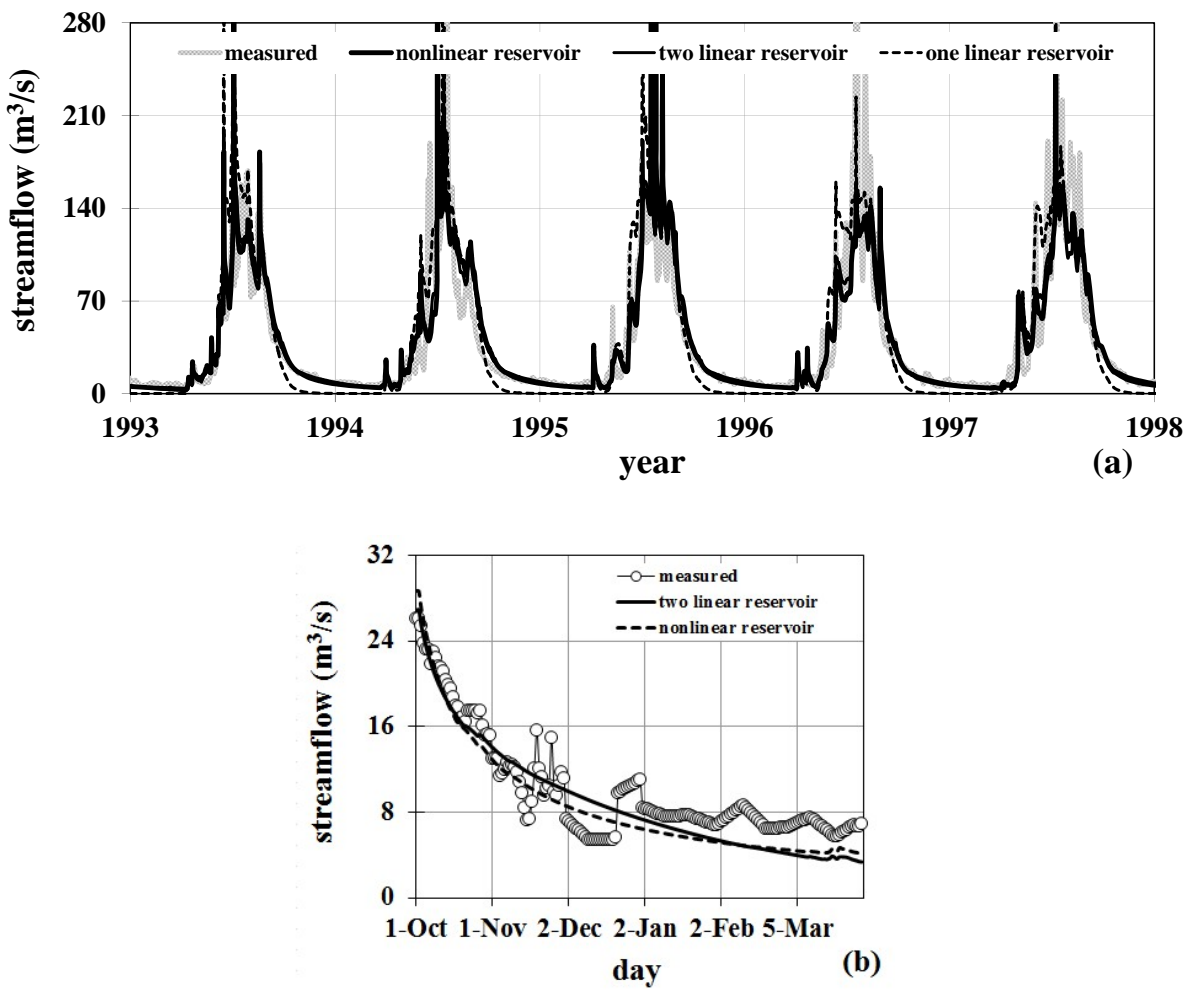

Fig. 4. (a) Comparison of simulated and measured streamflow processes for the validation stage. (b) One recession period from 1 October 1996 to 31 March 1997.

high-flow period, surface runoff is larger than base flow, when rainfall and snow/glacier melting occur.

The surface runoff responds closely to the recharge caused by rainfall events and snow/glacier melting. The pattern of surface runoff during the high-flow period obtained from the SWAT model demonstrates a fast and transient response to recharge; the surface runoff fluctuates. However, the base flow response during the high-flow period does not follow the same surface runoff response: its response is smooth (Fig. 5), following the typical pattern of base flow response as presented in the standard textbook (McCuen, 2005). Partington et al. (2012) found that an abrupt change in base flow occurs at the beginnings and ends of the rainfall events when using the HGS model. The reason may be that it is a typical synthetic catchment with smaller area and higher infiltration capacity, resulting in a rapid response for the base flow. During the low-flow period, both the base flow and surface runoff processes are relatively stable.

The average monthly base flow processes from 1966 to 1999 using a one-nonlinear reservoir model and the automatic digital filter technique (Nathan and McMahon, 1990) are shown in Fig. 6. The model-based base flow begins to 


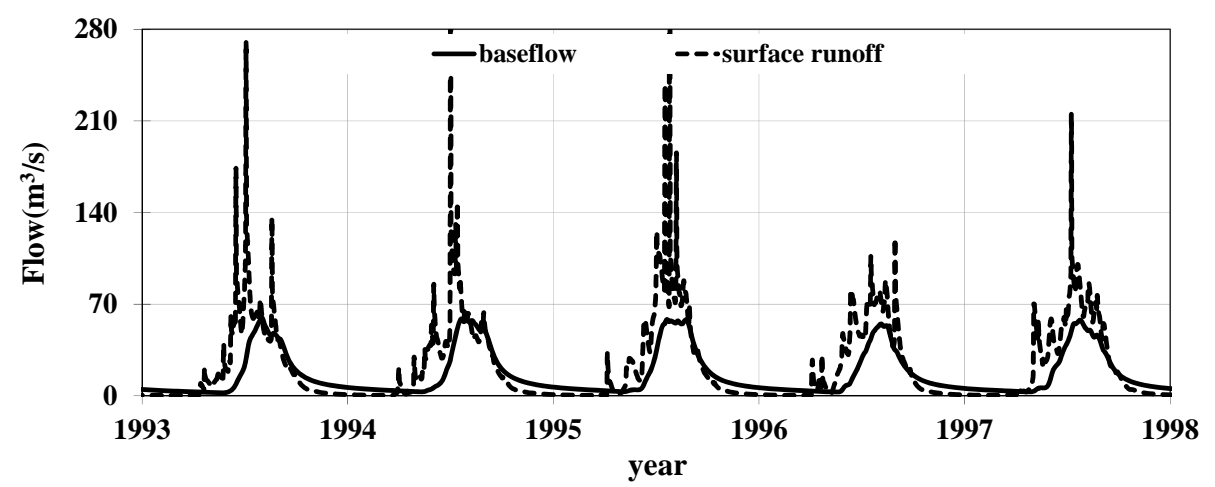

Fig. 5. The simulated base flow and surface runoff processes by one-nonlinear reservoir model.

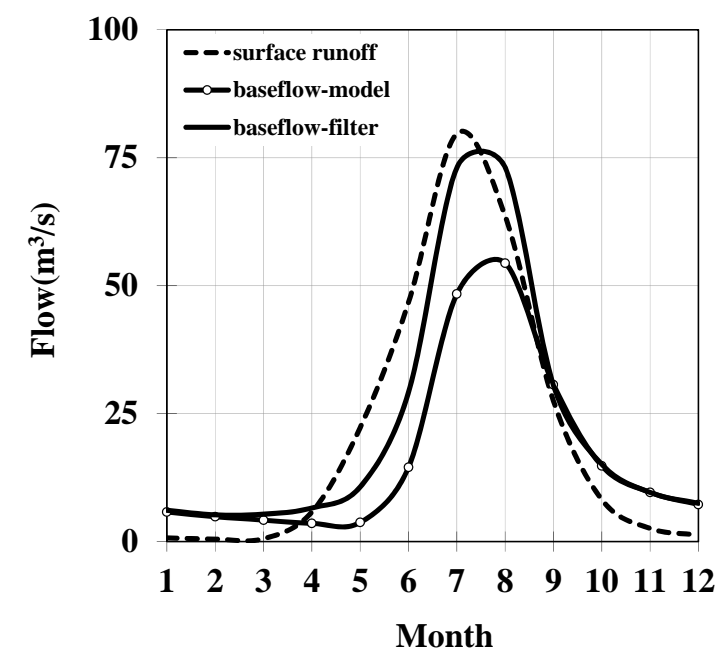

Fig. 6. A comparison of the average monthly base flow and surface runoff processes.

rise in May, peaks in August, and quickly returns to the sluggish receding stage. It indicates a groundwater recharge of rainfall and snow/glacier meltwater during the summer, which then releases slowly during the winter and spring. The aquifer storage fluctuates seasonally in the simulation. Interestingly, the onset of the rising limb in the one-nonlinear model-based surface runoff hydrograph differs from that of the base flow. The simulated surface runoff starts to rise in April, and reaches its peak in July, both events occurring earlier than the simulated base flow. The Manas River basin is dominated by snow/glacier meltwater, and the snowmelt usually starts in the middle of April. The surface runoff responds to snowmelt immediately, while the infiltration and recharge increase the time to groundwater discharge, resulting in a delay in the base flow component of streamflow.

The delays in the onset of base flow based on the onenonlinear model and linear reservoir model are much longer than the delays in the increase in filter-based base flow (Figs. 6 and 7). During this period, the soil in the Manas
Table 4. Statistical analysis for the base flow volume and index.

\begin{tabular}{lcccc}
\hline & Filter & $\begin{array}{c}\text { One-linear } \\
\text { reservoir }\end{array}$ & $\begin{array}{c}\text { Two-linear } \\
\text { reservoir }\end{array}$ & $\begin{array}{c}\text { One-nonlinear } \\
\text { reservoir }\end{array}$ \\
\hline $\begin{array}{l}\text { Base flow volume } \\
\left(10^{8} \mathrm{~m}^{3}\right)\end{array}$ & 7.20 & 5.63 & 5.62 & 5.38 \\
Base flow index & 0.60 & 0.45 & 0.45 & 0.44 \\
\hline
\end{tabular}

River basin is frozen. Luo et al. (2012) proposed that the infiltration and recharge from the soil profile during freezing and thawing eventually determines the onset of the rising limb. However, the freezing and thawing processes of soil have been insufficiently described in most watershed hydrological models, and these processes need more detailed description. During the peak time, the model- and filter-based base flow are similar, except for the one-linear reservoir model, which reaches the peak earlier.

Figure 7 illustrates the base flow hydrographs obtained using different models and the automatic digital filter technique. All of the approaches capture the change in slope of the recession in late September, when recharge to the groundwater from the upper soil layer ceases. The magnitude of the base flow differs among the four estimation methods. The one-linear reservoir model significantly underestimates the base flow during the low-flow period compared to the filterbased base flow, which might be the cause of the underestimated streamflow. The two-linear and one-nonlinear reservoir models reproduce the base flow properly during the lowflow period. During the high-flow period, the model-based base flow is smaller than the filter-based base flow.

The average annual base flow volumes and base flow index (BFI) calculated as the long-term ratio of the base flow volume to the total streamflow volume, according to the definition of the Institute of Hydrology (1980), are listed in Table 4. The average annual base flow volume determined using the digital filter separation method is $7.2 \times 10^{8} \mathrm{~m}^{3}$, and the simulated values using the one-linear, two-linear and one-nonlinear reservoir models are $5.63 \times 10^{8} \mathrm{~m}^{3}, 5.62 \times 10^{8} \mathrm{~m}^{3}$, and $5.38 \times 10^{8} \mathrm{~m}^{3}$, 


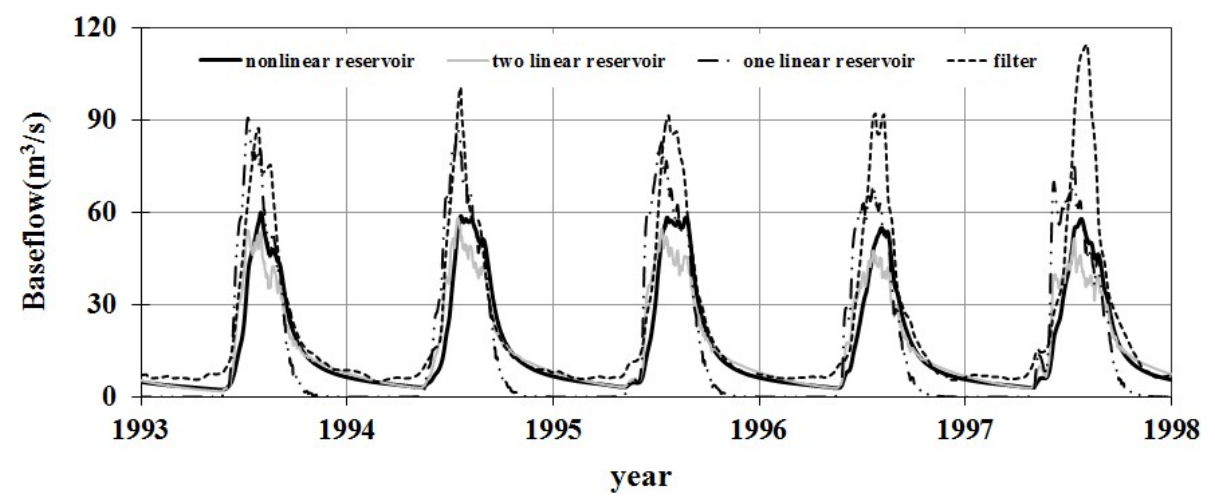

Fig. 7. The base flow processes generated using the model- and filter-based approaches.

respectively. The one-linear and two-linear reservoir models give similar annual base flow volumes that are slightly larger than that from the one-nonlinear reservoir model. The automatic digital filter method gives a much larger base flow volume than the model-based approaches.

The base flow indices for the one-linear, two-linear and one-nonlinear reservoir models are $0.45,0.45$, and 0.44 , respectively, and the filter-based index is 0.60 . The model estimates in this study are 22 to $25 \%$ lower than those of the automatic digital filter method. Wu and Johnston (2007) found that the SWAT estimate is lower than that of the Rutledge method, and attributed it primarily to the long time lag between the winter snowpack accumulation and the spring snowmelt events. In this period, the Rutledge method includes base flow due to its assumptions about the temporal offset between precipitation events and the runoff response, while the SWAT model method more correctly treats this as surface runoff. Snowmelt is an important component of streamflow in the Manas River basin, which may be the reason for the underestimation of the SWAT method in this study. Additionally, the streamflow in the SWAT model is comprised of surface runoff, lateral subsurface flow, and base flow (groundwater discharge), while in the digital filter method, streamflow is distinguished as direct runoff (streamflow component varying with high frequency, usually associated with surface runoff and interflow) and base flow (streamflow component varying with low frequency, usually associated with groundwater discharge and probably also the melting water). This may be the reason why the digital filter method gives a much larger base flow volume than the model-based approaches. Direct comparison of the base flow of the SWAT model and the filter might not be appropriate. However, the result of the filter is still a reference for the SWAT model due to availability of and difficulty in measuring the base flow data.

\subsection{The groundwater storage}

The averaged monthly groundwater storage calculated by the SWAT model using the nonlinear approach for MRB is

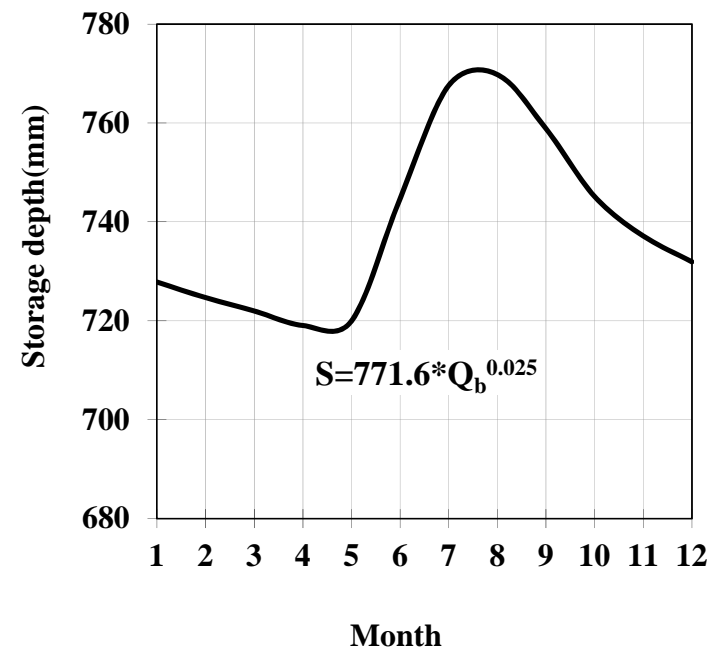

Fig. 8. The storage depth calculated using the nonlinear model approach.

shown in Fig. 8. The maximum, minimum, and mean storage water depths are $782.1,702.1$, and $737.5 \mathrm{~mm}$, respectively. There is seasonal variation in the groundwater storage. It begins to rise in May, reaches its peak in August, starts to decrease in September, and reaches its lowest value in April. The seasonal pattern of storage water depth is related to the possible times for recharge. The sudden rise in storage volume in May could be the result of recharge by snowmelt. It continues to increase due to additional snow/glacier melting. In July, the maximum recharge occurs due to greater glacier melting and rainfall. Then the rainfall and glacier meltwater starts to decrease, as does the recharge. In September, the recharge is lower than the discharge, and the storage water depth begins to decline. From October to the following April, the recharge ceases, but the groundwater discharge continues, and the storage water depth continues to decrease. 
Table 5. Statistical analysis for the exponent $b$ of the aquifer storage-discharge function.

\begin{tabular}{|c|c|c|c|c|c|c|c|c|}
\hline \multirow{2}{*}{$b$} & \multirow{2}{*}{ Catchments } & \multicolumn{4}{|c|}{$b$} & \multicolumn{3}{|c|}{$R^{2}$} \\
\hline & & $\max$ & $\min$ & mean & std dev & $\max$ & $\min$ & mean \\
\hline $0.0-0.1$ & 38 & 0.09 & 0.02 & 0.04 & 0.02 & 0.90 & 0.27 & 0.65 \\
\hline $0.1-0.2$ & 8 & 0.19 & 0.11 & 0.15 & 0.03 & 0.88 & 0.36 & 0.74 \\
\hline $0.2-0.3$ & 1 & 0.25 & 0.25 & 0.25 & - & 0.63 & 0.63 & 0.63 \\
\hline $0.3-0.4$ & 3 & 0.40 & 0.37 & 0.39 & 0.02 & 0.81 & 0.61 & 0.68 \\
\hline $0.4-0.5$ & 4 & 0.48 & 0.43 & 0.47 & 0.03 & 0.88 & 0.88 & 0.88 \\
\hline $0.5-0.6$ & 2 & 0.54 & 0.53 & 0.54 & 0.01 & 0.75 & 0.36 & 0.55 \\
\hline $0.6-0.7$ & 4 & 0.69 & 0.61 & 0.67 & 0.04 & 0.84 & 0.82 & 0.83 \\
\hline $0.7-0.8$ & 5 & 0.80 & 0.72 & 0.77 & 0.03 & 0.84 & 0.77 & 0.80 \\
\hline $0.8-0.9$ & 3 & 0.86 & 0.82 & 0.84 & 0.02 & 0.80 & 0.70 & 0.75 \\
\hline $0.9-1.0$ & 9 & 1.00 & 0.95 & 0.99 & 0.02 & 0.92 & 0.75 & 0.83 \\
\hline $0.0-1.0$ & 78 & 1.00 & 0.02 & 0.32 & 0.35 & 0.92 & 0.27 & 0.71 \\
\hline
\end{tabular}

\subsection{Variation in the parameters $a$ and $b$}

To investigate the variability in the coefficient $a$ and the exponent $b$ in the exponential aquifer storage-discharge function among different catchments, $a$ and $b$ were optimized for 78 catchments in this region, with different physical features such as drainage area and glacier cover ratio, using the observed daily flow records.

The statistics indicate that the exponent $b$ varies significantly among catchments (Table 5). For the investigated catchments, the mean value for the exponent $b$ is 0.32 . Wittenberg (1994) found that the exponent $b$ ranges from 0.11 to 0.91 , with a typical value of 0.4 for 17 gauging stations in northwestern Germany, and Chapman (1999) found that it varies between 0.31 and 0.63 for 11 catchments in eastern Australia. The analysis of observed flow recession in numerous rivers in different hydrological regimes (Wittenberg, 1994, 1999) yielded values of $b<1$, peaking between 0.3 and 0.4 , with a mean value of $b \approx 0.5$. In our study, the exponent $b$ varies more widely, from 0.02 to 1.0 (Table 5), with a skewed distribution. The smaller exponent indicates that the aquifer discharge is more sensitive to changes in the aquifer storage, based on Eq. (1). When $b$ equals 1.0, the equation implies that the discharge changes linearly with the storage. The exponent $b$ reflects the influences of the aquifer properties on the discharge. Harman and Sivapalan (2009) indicated that $b$ is never below 0.5 in the homogeneous, planar hill slopes. Chapman (1999) suggested that smaller exponents may be attributed to the horizontal and vertical convergence of the flow in source areas, and the value of 0.5 for $b$ appears to be a standard power exponent for unconfined aquifers (Wittenberg, 1999; Aksoy and Wittenberg, 2011). These might imply that aquifer properties are more varied in this region, and the exponent $b$ should be specific for a catchment, not simply the mean value of 0.32 or the suggested value of 0.5 . Nevertheless, the coefficients of determination $\left(R^{2}\right)$ of the catchments indicate that for most catchments,
Table 6. Correlation matrix for the parameter and the basin features.

\begin{tabular}{llll}
\hline & $a$ & $\begin{array}{c}\text { Catchment } \\
\text { area }\end{array}$ & $\begin{array}{r}\text { Glacier } \\
\text { area }\end{array}$ \\
\hline $\begin{array}{l}a \text { Pearson correlation } \\
\text { Sig. (two-tailed) }\end{array}$ & 1 & & \\
$N$ & 78 & & \\
Catchment area Pearson correlation & $0.36^{* *}$ & 1 & \\
Sig. (two-tailed) & 0.002 & & \\
$N$ & 78 & 78 & \\
Glacier area Pearson correlation & $0.26^{*}$ & $0.73^{* *}$ & \\
Sig. (two-tailed) & 0.046 & 0.000 & \\
$N$ & 68 & 68 & \\
& 68
\end{tabular}

the nonlinear exponential function describes the recession processes very well.

The values of the parameter $a$ range from 6.29 to 5698 , with a mean value of 463.3 in this study. These values vary by orders of magnitude, which may be due to the tremendous changes in the catchment area (Table 1). The lower $a$ values indicated that basin storage is much lower, and that the values of parameter $a$ are related to catchment area (Wittenberg, 1994). Regression analysis indicates that $a$ is correlated not only to the catchment area but also to the glacier area in the study catchments (Table 6). The parameter $a$ may vary seasonally, which may be attributed to the variation in the hydraulic gradient caused by the changes in evapotranspiration losses (Datta et al., 2012). The maximum value of parameter $a$ (monthly averages) is about 16 times larger than the minimum (Aksoy and Wittenberg, 2011). This indicates that there is a wide range of variation for parameter $a$. 


\section{Conclusions}

This study indicates that the nonlinear aquifer storagedischarge approach performs as well as the two-linear reservoir approach in the Manas River basin, Xinjiang, China, and has the advantage of a simpler form and only two parameters that must be calibrated. The parameters $a$ and $b$ in the exponential function that describe the aquifer storage-discharge relationship can be optimized through the observed streamflow data during the recession periods independent of the SWAT model.

The parameters $a$ and $b$ vary significantly among the rivers in the arid region of northwestern China. The parameter $b$ ranges from 0.015 to 1 , with a mean value of 0.32 and a standard deviation of 0.35 . Of the 78 basins investigated, almost half of their $b$ values fall between 0 and 0.1 . The maximum value for parameter $a$ is 5698, and the minimum value just 6.29 with a mean value of 463.3 , which are mainly dependent on the basin and glacier areas. Overall, the exponential aquifer storage-discharge function fits the recession processes very well for most of the catchments.

Acknowledgements. This study is supported partially by the Natural Science Foundation of China (grant No. 41130641), the 973 Program of China (grant No. 2010CB951002), and the Project of the National Eleventh Five-Year Research Program of China (grant No. 2012BAC19B07).

Edited by: S. Archfield

\section{References}

Aksoy, H. and Wittenberg, H.: Nonlinear baseflow recession analysis in watersheds with intermittent streamflow, Hydrolog. Sci. J., 56, 226-237, 2011.

Arnold, J. G., Allen, P. M., Muttiah, R., and Bernhardt, G.: Automated base flow separation and recession analysis techniques, Ground Water, 33, 1010-1018, 1995.

Arnold, J. G., Muttiah, R. S., Srinivasan, R., and Allen, P. M.: Regional estimation of base flow and groundwater recharge in the Upper Mississippi River basin, J. Hydrol., 227, 21-40, 2000.

Arnold, J. G. and Fohrer, N.: SWAT2000: Current capabilities and research opportunities in applied watershed modeling, Hydrol. Process., 19, 563-572, 2005.

Chapman, T.: A comparison of algorithms for stream flow recession and baseflow separation, Hydrol. Process., 13, 701-714, 1999.

Criss, R. E. and Winston, W. E.: Do Nash values have value? Discussion and alternate proposals, Hydrol. Process., 2723-2725, 2008.

Datta, A. R., Bolisetti, T., and Balachandar, R.: Automated linear and nonlinear reservoir approaches for estimating annual baseflow, J. Hydrol. Eng.-ASCE, 17, 554-564, 2012.

Fenicia, F., Savenije, H. H. G., Matgen, P., and Pfister, L.: Is the groundwater reservoir linear? Learning from data in hydrological modelling, Hydrol. Earth Syst. Sci., 10, 139-150, doi:10.5194/hess-10-139-2006, 2006.
Ferket, B. V. A., Samain, B., and Pauwels, V. R. N.: Internal validation of conceptual rainfall-runoff models using baseflow separation, J. Hydrol., 381, 158-173, 2010.

Haberlandt, U., Klocking, B., Krysanova, V., and Becker, A.: Regionalisation of the base flow index from dynamically simulated flow components - a case study in the Elbe River Basin, J. Hydrol., 248, 35-53, 2001.

Harman, C. J. and Sivapalan, M.: A similarity framework to assess controls on shallow subsurface flow dynamics in hillslopes, Water Resour. Res., 45, W01417, doi:10.1029/2008WR007067, 2009.

Institute of Hydrology: Low Flow Studies Report, Wallingford, UK, 1980.

Krause, P., Boyle, D. P., and Bäse, F.: Comparison of different efficiency criteria for hydrological model assessment, Adv. Geosci., 5, 89-97, doi:10.5194/adgeo-5-89-2005, 2005.

Legates, D. R. and McCabe Jr., G. J.: Evaluating the use of "goodness-of-fit" measures in hydrologic and hydroclimatic model validation, Water Resour. Res., 35, 233-241, 1999.

Longobardi, A. and Villani, P.: Baseflow index regionalization analysis in a mediterranean area and data scarcity context: Role of the catchment permeability index, J. Hydrol., 355, 63-75, 2008.

Luo, Y., Arnold, J., Allen, P., and Chen, X.: Baseflow simulation using SWAT model in an inland river basin in Tianshan Mountains, Northwest China, Hydrol. Earth Syst. Sci., 16, 1259-1267, doi:10.5194/hess-16-1259-2012, 2012.

Lyne, V. and Hollick, M.: Stochastic time variable rainfall runoff modeling, in: Hydrology and Water Resources Symposium Perth 1979 Proceedings, National Committee on Hydrology and Water Resources of the Institution of Engineers, Australia, 89-92, 1979.

McCuen, R. H.: Hydrologic Analysis and Design, Prentice Hall, 2005.

Moore, R. D.: Storage-outflow modelling of streamflow recessions, with application to a shallow-soil forested catchment, J. Hydrol., 198, 260-270, 1997.

Moriasi, D. N., Arnold, J., Van Liew, M. W., Bingner, R. L., Harmel, R. D., and Veith, T. L.: Model evaluation guidelines for systematic quantification of accuracy in watershed simulations, T. Am. Soc. Agr. Biol. Eng., 50, 885-900, 2007.

Mwakalila, S., Feyen, J., and Wyseure, G.: The influence of physical catchment properties on baseflow in semi-arid environments, $\mathrm{J}$. Arid Environ., 52, 245-258, 2002.

Nathan, R. J. and McMahon, T. A.: Evaluation of automated techniques for baseflow and recession analysis, Water Resour. Res., 26, 1465-1473, 1990.

Neitsch, S. L., Arnold, J. G., Kiniry, J. R., Williams, J. R., and King, K. W.: Soil water assessment tool theoretical document, version 2000, Grassland, Soil and Water Research Laboratory, Temple, Texas, 506 pp., 2002.

Partington, D., Brunner, P., Simmons, C. T., Therrien, R., Werner, A. D., Therrien, R., Maier, H. R., and Dandy, G. C.: Evaluation of outputs from automated baseflow separation methods against simulated baseflow from a physically based, surface water-groundwater flow model, J. Hydrol., 458-459, 28-39, 2012.

Santhi, C. and Allen, P. M.: Regional estimation of base flow for the conterminous United States by hydrologic landscape regions, J. Hydrol., 351, 139-153, 2008. 
Werner, P. W. and Sundquist, K. J.: On the groundwater recession curve for large watersheds, in IASH General Assembly, Brussels, IAHS Publ., 33, 202-212, 1951.

Wittenberg, H.: Nonlinear analysis of flow recession curves, in: FRIEND: Flow Regimes from International Experimental and Network Data, Proceeding of the Braunschweig conference, October 1993, IAHS Publ. no. 221, IAHS, Wallingford: IAHS Press, 61-67, 1994.
Wittenberg, H.: Baseflow recession and recharge as nonlinear storage processes, Hydrol. Process., 13, 715-726, 1999.

$\mathrm{Wu}, \mathrm{K}$. and Johnston, C. A.: Hydrologic response to climatic variability in a Great Lakes Watershed: A case study with the SWAT model, J. Hydrol., 337, 187-199, 2007.

Yang, Z. N.: Glacier water resources in China, Gansu Science and Technology Press, 1991. 